\title{
DIVERS@!
}

\section{CONHECIMENTOS E PRÁTICAS NA UTILIZAÇÃO DE AGROTÓXICOS E SEU IMPACTO NA SAÚDE DE ASSENTADOS DE JARDIM ALEGRE/PR.} KNOWLEDGE AND PRACTICE IN THE USE OF PESTICIDES AND THEIR IMPACT ON THE HEALTH OF THE SETTLED RESIDENTS IN THE TOWN OF JARDIM ALEGRE IN PARANA.

\author{
Cleversom da Silva Souza 1
}

Cristiane Carolina Sehnem Souza ${ }^{2}$

Milene Zanoni da Silva Vosgerau ${ }^{3}$

\begin{abstract}
RESUMO
Esta experiência se desenvolveu no assentamento oito de abril situado em Jardim Alegre - Paraná, durante o período compreendido de fevereiro a abril de 2011, tendo como objetivo identificar os conhecimentos e práticas na utilização de agrotóxicos e seu impacto na saúde dos assentados, abordando a importância da educação e informação na vida dos trabalhadores. Por meio de entrevistas com questionários estruturados foram levantadas questões pertinentes à educação voltada para a segurança e saúde do trabalhador do campo, relacionada ao uso e aplicação de agrotóxicos. Os resultados apontam que os agricultores entrevistados possuíam baixo nível educacional e carência de informações quanto ao uso correto e seguro dos produtos químicos. Mais da metade dos entrevistados notou algum problema de saúde relacionado à pulverização dos agrotóxicos, sendo que os sintomas agudos mais frequentes foram problemas estomacais e dores de cabeça. Os achados deste estudo trazem à tona a urgência e relevância ambiental, social e sanitária - de políticas públicas para o enfrentamento dos problemas do uso de agrotóxicos no Brasil.
\end{abstract}

Palavras-chave: Conhecimentos, Atitudes e Prática em Saúde, Educação em Saúde, Agrotóxicos.

\section{ABSTRACT}

This experience has developed in the Settlement 8 de Abril located in Jardim Alegre, in Parana, from February through April in 2011, aiming to identify the knowledge and handling in the use of pesticides and their impact on the health of the settled residents, focusing the importance of the education and information in the lives of these workers. Through interviews with structured questionnaires, issues were raised concerning education focused on safety and health of the farming worker, towards the use and application of pesticides. The results indicate that the interviewed farmers had a low educational level and lack of information about the correct and safe use of chemicals. More than half of the participants felt some health problem related to the spraying of pesticides, and the most common acute symptoms were stomachal problems and headaches. The findings bring out the environmental, social and health urgency and relevance of public policies to fight the problems of pesticide use in Brazil.

Keywords: Health Knowledge, Attitudes, Practice, health education, Pesticides.

1. Engenheiro Agrônomo pela UFPR, Engenheiro de Segurança do Trabalho pela PUC do Paraná, Especialista em Educação do Campo-EaD pela UFPR Pólo UAB de Paranaguá, Extensionista da FUNDAÇÃO TERRA / EMATER Jardim Alegre - Paraná - Brasil, telefone: (43) 9629-0392, e-mail: kessosouza@yahoo.com.br.

2. Engenheira Agrônoma pela UFPR, Ivaiporã - Paraná - Brasil, telefone (41) 9975-2443, e-mail: crisehnem@yahoo.com.br.

3. Professora adjunta do Departamento de Saúde Comunitária da UFPR. 


\section{DIVERS@!}

\section{INTRODUÇÃO}

A agricultura tem enfrentado grandes mudanças tecnológicas em curto espaço de tempo, dentre elas o uso da mecanização em praticamente todos os processos, a utilização de agroquímicos em grandes quantidades, até a mais recente técnica a biotecnologia, destacandose os transgênicos. Com a modernização do campo, o processo de produção ficou cada vez mais complicado e dependente dos agrotóxicos. (MESQUITA; MENDES, 2009).

Agrotóxicos são substâncias químicas artificiais usadas tanto na agricultura, quanto na pecuária, sendo tóxicos em graus variados ao homem, aos animais e ao ambiente. Sua empregabilidade se dá na proteção de plantas de interesse contra os ataques de predadores como insetos, fungos, bactérias e no controle de outras plantas, chamadas geralmente de ervas daninhas ou invasoras (ANDALÓ et al, 2004).

Segundo a Lei Federal n $\mathrm{n}^{0} 7.802$ o termo "agrotóxicos" é definido como: produtos e componentes de processos físicos, químicos ou biológicos destinados ao uso nos setores de produção, armazenamento e beneficiamento de produtos agrícolas, nas pastagens, na proteção de florestas nativas ou implantadas e de outros ecossistemas e também em ambientes urbanos, hídricos e industriais, cuja finalidade seja alterar a composição da flora e da fauna, a fim de preservá-la da ação danosa de seres vivos considerados nocivos, bem como substâncias e produtos empregados como desfolhantes, dessecantes, estimuladores e inibidores do crescimento. A classificação dos produtos agrotóxicos é de acordo com a toxicidade, ficando divididos em classes: I- extremamente tóxico (faixa vermelha); II - altamente tóxica (faixa amarela); III - medianamente tóxica (faixa azul) e IV - pouco tóxica (faixa verde) (BRASIL, 1989).

Os "defensivos agrícolas" também podem ser classificados de acordo com o uso ou controle, por exemplo, os bactericidas para controle de bactérias, nematicidas para controle de nematóides, herbicidas para o controle do "mato", fungicidas para controle de doenças ocasionadas por fungos, Inseticidas para controlar os insetos, acaricidas para o controle de ácaros, entre outros (VAZ etal., 1996). 


\section{DIVERS@!}

O Brasil é um grande produtor agrícola e apresenta altas taxas de intoxicação por agrotóxicos, seja no meio rural ou urbano, devido às deficiências na estrutura social (TRAPÉ, 2003). Segundo os dados do Ministério da Saúde (2009), no período de 1999 a 2009, foram registrados 5453 intoxicações por agrotóxicos, as quais ocasionaram 166 óbitos no país.

De acordo com os dados do Sindicato Nacional da Indústria de Produtos para Defesa Agrícola, o Brasil foi o segundo maior consumidor de defensivos do mundo em 2010, ficando atrás apenas dos Estados Unidos. Estima-se que o crescimento das vendas para os próximos anos supere os montantes americanos, o que dará ao país o título de maior consumidor mundial de produtos fitossanitários (SINDAG, 2011).

É largamente conhecido que os agrotóxicos conferem risco à saúde de quem os utiliza. Para que ocorra intoxicação é necessário levar em consideração vários fatores, tais como: (a) tempo de exposição, ou seja, o tempo em que o trabalhador fica exposto ao produto; (b) dosagem, isto é, a quantidade do produto que o indivíduo teve contato; a classe toxicológica do agrotóxico; (c) características do indivíduo exposto como: idade, sexo, peso, entre outros. A combinação destes fatores leva a classes de intoxicações diferentes, que são três: aguda, subaguda ou crônica (OPAS/OMS, 1996).

A intoxicação aguda se caracteriza por aparecimentos repentinos dos sintomas, através de excessiva exposição, em curto período a produtos altamente tóxicos, com diagnóstico objetivo. Na subaguda a exposição é leve ou moderada a produtos altamente tóxicos, ocasionando o surgimento de sintomas mais lentamente, com diagnósticos vagos e subjetivos. Já na intoxicação crônica, os sintomas surgem de forma mais lenta, comparada as outras formas de intoxicação, variando de meses a anos, através de leves ou moderadas exposições a produtos tóxicos ou uma mistura de produtos, podendo levar a danos irreversíveis como neoplasias e paralisias (DOMINGUES et al., 2004).

O trabalhador rural tem muito contato com diversos tipos de agrotóxicos, tendo como resultado, ao longo do tempo, sintomas combinados e específicos podendo ser confundidos com outras doenças, o que leva à tratamentos inadequados. (OPAS/OMS, 1996). De acordo com Carraro (1997), mesmo que um produto seja pouco tóxico, mas se usado em altas concentrações 


\section{DIVERS@!}

de seu princípio ativo, pode ser mais agressivo à saúde humana que outro produto altamente tóxico, aplicado em baixa concentração de princípio ativo.

No Brasil, segundo IBGE (2009), observa-se que existe uma grande quantidade de trabalhadores analfabetos e semi-analfabetos que fazem uso de agrotóxicos em suas lavouras, expondo-se de maneira direta ou indireta, aumentando as chances de ocorrências de intoxicações e/ou doenças crônicas. Mais de 50\% das propriedades brasileiras não possuem orientações técnicas, de nenhuma forma, muito menos quanto ao uso correto de agroquímicos, ficando os produtores expostos aos perigos destes produtos.

Nos assentamentos brasileiros, dentre as pessoas com 18 anos ou mais, aproximadamente $15 \%$ nunca frequentaram escolas e $45 \%$ frequentaram apenas as séries de $1^{\mathrm{a}}$ a $4^{\mathrm{a}}$ do ensino fundamental, então aproximadamente $60 \%$ dos camponeses nesta faixa etária possuem nenhuma ou pouca escolaridade (MEC, 2005).

Assim, o baixo nível de instrução dos agricultores associado à complexidade das informações descritas nos rótulos dos agrotóxicos criam uma importante barreira à comunicação sobre o seu uso correto e os riscos na saúde e no meio ambiente (FEHLBERG et al., 2003). Como consequência desta situação, muitos dos agricultores desconhecem a importância da utilização dos equipamentos de proteção individual, ou se conhecem, não utilizam ou empregam de maneira inadequada. (SCATENA, 2006).

Desta forma, este trabalho objetivou identificar os conhecimentos e práticas na utilização de agrotóxicos e seu impacto na saúde dos assentados, abordando a importância da educação e informação na vida desta classe de trabalhadores.

\section{MATERIAL E MÉTODOS}

Este trabalho foi realizado no entre os meses de fevereiro e abril de 2011, no assentamento chamado "Oito de Abril”, situado no município de Jardim Alegre que, de acordo com Denez (2010), ocupa uma área de 5, 8 mil alqueires, aproximadamente 40\% da área territorial do município. Sua população estimada no ano de 2010 era de 12.325 habitantes 


\section{DIVERS@!}

(IBGE, 2009). O município localiza-se na região centro oeste do norte do Paraná no Vale do Ivaí, limitando-se ao norte com Lidianópolis e Lunardelli, ao sul com Ivaiporã, ao Leste com Grandes Rios e a Oeste com Godoy Moreira, Iretama e Nova Tebas (PREFEITURA MUNICIPAL DE JARDIM ALEGRE, 2011). O assentamento Oito de Abril, conforme o site do movimento MST (2010) possui uma população que corresponde aproximadamente $40 \%$ da população total do município.

O assentamento possui aproximadamente 555 famílias, vindas de várias partes do país, com diferentes raças e etnias. Essas famílias foram assentadas aproximadamente a 4 anos, sendo que cada uma recebeu um lote de aproximadamente 5 a 7 alqueires de área. Somente agora começaram as construções das casas de alvenaria e o acesso ao primeiro investimento, PRONAF (Programa Nacional de Fortalecimento da Agricultura Familiar para agricultores assentados). Vivem principalmente da produção de leite, milho e feijão, e de produtos para o auto-consumo, como mandioca, batata-doce, arroz, cana-de-açúcar, criação de galinhas, suínos.

O delineamento do estudo foi transversal e a coleta de dados se deu por meio da realização de entrevistas com formulários estruturados, os quais tiveram suas respostas anotadas pelo entrevistador. A seleção da amostra se deu de forma aleatória, por meio de visitas domiciliares ou durante a participação dos entrevistados em eventos ocorridos dentro do território estudado. Os critérios de inclusão da pesquisa foram: ser morador do assentamento, lidar diretamente com agrotóxicos e ter mais de 18 anos. Foram entrevistados 40 agricultores, pelo menos um de cada comunidade, para garantir maior representatividade.

As variáveis analisadas por meio da entrevista foram: (1) sócio-demográficas; (2) uso de agrotóxicos na propriedade; (3) conhecimentos e práticas na utilização do agrotóxico; (4) condição de saúde.

A análise dos dados foi descritiva, feita por meio de frequência absoluta e relativa. Quanto à questão ética, após leitura do Termo de consentimento livre e esclarecido (TCLE), todos os sujeitos aceitaram responder as questões do questionário elaborado e autorizaram a publicação das informações fornecidas. 


\section{DIVERS@!}

\section{RESULTADOS E DISCUSSÃO CONSIDERAÇÕES}

Todos os entrevistados neste trabalho eram do sexo masculino. O grau de escolaridade dos entrevistados era baixo conforme demonstrado na tabela 1, sendo que 15\% da população era analfabeta e $45 \%$ possuía ensino fundamental incompleto. Sabe-se que este dado é um fator relacionado diretamente ao aumento de intoxicação por agrotóxicos, pois limita as pessoas compreenderem as informações contidas nos rótulos, o que por sua vez pode também influenciar na percepção dos riscos. Estes resultados corroboram as informações do Ministério da Educação (BRASIL, 2005) e Instituto Brasileiro de Geografia e Estatística (IBGE, 2009), os quais ressaltam que o baixo nível de escolaridade está entre os fatores socioeconômicos que potencializam o risco de intoxicação. Quanto à faixa etária, a média foi de aproximadamente 44 anos, com idade mínima de 22 anos e máxima de 70 anos.

TABELA 1- DISTRIBUIÇÃO DAS CARACTERÍSTICAS SOCIODEMOGRÁFICAS DE ASSENTADOS DE JARDIM ALEGRE, 2011.

\begin{tabular}{|lllr|}
\hline \multicolumn{1}{|c}{ Variável } & & $\mathrm{n}$ & \multicolumn{1}{c}{$\%$} \\
\hline & Analfabeto & 06 & 15,0 \\
& Fundamental incompleto & 18 & 45,0 \\
Grau de Escolaridade & Fundamental completo & 05 & 12,5 \\
& Médio Incompleto & 02 & 5,0 \\
& Médio completo & 08 & 20,0 \\
& Superior Completo & 01 & 2,5 \\
& $22-30$ & 04 & 10,0 \\
& $31-40$ & 12 & 30,0 \\
Idade & $41-50$ & 11 & 27,5 \\
& $51-60$ & 10 & 25,0 \\
& $61-70$ & 03 & 7,5 \\
\hline
\end{tabular}

FONTE: Os autores

Semelhante à realidade nacional, a população de estudo seguiu os mesmos padrões de agricultura familiar, como mostra a tabela 2, que aponta que a maior parte dos entrevistados (62,5\%) desempenhava tanto a produção agrícola quanto a produção de leite, e 30\% tinha como atividade principal a lavoura. Ressalta-se que em todas as atividades eram usados produtos 


\section{DIVERS@!}

químicos no processo produtivo, com a ressalva de que na pecuária de leite a necessidade de uso é menor. Estes resultados mostram que, como qualquer agricultor familiar, este grupo entrevistado possui maior vulnerabilidade, quanto à utilização de agrotóxicos, quando comparado à população urbana, pois estão diretamente ligados a atividades agropecuárias, expostos a produtos químicos em maiores frequências.

Outro dado relevante é que $100 \%$ do grupo amostrado responderam que uma ou duas pessoas da família manuseavam estes produtos.

TABELA - 2 - INFORMAÇÕES SOBRE AS PRINCIPAIS ATIVIDADES

DESENVOLVIDAS POR AGRICULTORES ASSENTADOS DE JARDIM ALEGRE, 2011

\begin{tabular}{|l|l|c|c|}
\hline \multicolumn{1}{|c}{ Variável } & & n & $\%$ \\
\hline $\begin{array}{l}\text { Principais atividades desenvolvidas na } \\
\text { propriedade }\end{array}$ & Lavoura & 12 & 30,0 \\
\hline & Pecuária Leiteira & 03 & 7,5 \\
\hline
\end{tabular}

FONTE: Os autores

Na tabela 3 nota-se que $80 \%(n=32)$ dos 40 entrevistados receberam ou recebem algum tipo de informação quanto aos riscos de se utilizar agrotóxicos, tanto para a saúde quanto para o meio ambiente, porém 62,5\% $(n=20)$ desses não consideram estas informações suficientes para garantir o uso com segurança. A leitura dos rótulos dos produtos também é um importante meio de informações, pois nestes encontram-se dosagens, recomendações para utilização de equipamentos de proteção individual, descarte das embalagens, entre outros.

Ainda na tabela 3, cerca de $77,5 \%$ dos entrevistados relataram ler os rótulos dos agrotóxicos sempre ou às vezes, e destes, como se pode observar na tabela 4 , praticamente $60 \%$ possuíam algum tipo de dificuldade, na compreensão das informações contidas nos rótulos. Das pessoas que leem a bula, mais de $83 \%$ não atende de alguma forma as recomendações contidas nestas, o que justifica, em muitos casos, o descarte incorreto das embalagens e o nível de intoxicação. A pequena percentagem de agricultores que leem os rótulos e o baixo nível de entendimento das informações contidas neste pode ser explicada pela baixa escolaridade dentro desta comunidade (Oliveira-Silva et al., 2001). De acordo com FEHLBERG et al, 2003, os níveis de escolaridade e a linguagem, muitas vezes excessivamente técnicas, descritas nos 


\section{DIVERS@!}

rótulos dos agrotóxicos, prejudicam a compreensão dos agricultores, o que dificulta o seu uso adequado.

Conhecer o grau de percepção dos riscos é de suma importância para que se possa chegar a alguns fatores desencadeadores de acidentes, ou seja, intoxicações levadas por atos inseguros, gerados muitas vezes pelo excesso de confiança. A pesquisa mostrou que apesar de 95\% dos entrevistados considerarem perigoso o uso dos produtos químicos e $85 \%$ alegarem saber o que é Equipamento de Proteção Individual (EPI), menos de 10\% utilizam estes equipamentos em suas práticas (tabela 5). Os motivos principais da não utilização foram por descuido ou por desconforto (45\%). No Brasil, é comum, principalmente nas pequenas comunidades rurais, deparar-se com agricultores manipulando e a aplicando agrotóxicos sem estar usando EPI, muitas vezes por causa da inadequação destes equipamentos, provocando desconforto térmico, tornando incômodo o seu uso (VEIGA et al., 2007)

TABELA 3 - GRAU DE INFORMAÇÕES DOS AGRICULTORES ASSENTADOS DE JARDIM ALEGRE A RESPEITO DO USO DE AGROTÓXICOS, 2011

\begin{tabular}{|c|c|c|c|}
\hline Variáveis & & $\mathbf{n}$ & $\%$ \\
\hline \multirow{2}{*}{$\begin{array}{l}\text { Possui informações dos riscos de se utilizar } \\
\text { agrotóxicos? }(\mathrm{N}=40)\end{array}$} & Possui & 32 & 80,0 \\
\hline & Não Possui & 08 & 20,0 \\
\hline \multirow{3}{*}{$\begin{array}{l}\text { Considera as informações recebidas suficientes } \\
\text { para utilizar os agrotóxicos com segurança? } \\
(n=32)\end{array}$} & $\operatorname{Sim}$ & 10 & 31,2 \\
\hline & Não & 20 & 62,5 \\
\hline & Parcialmente & 02 & 6,3 \\
\hline \multirow{3}{*}{$\begin{array}{l}\text { Costuma ler a bula (rótulo) dos produtos? } \\
(\mathrm{N}=40)\end{array}$} & Sempre & 23 & 57,5 \\
\hline & Não & 09 & 22,5 \\
\hline & As Vezes & 08 & 20,0 \\
\hline
\end{tabular}

FONTE: Os autores

TABELA 4 - GRAU DE COMPREENSÃO DAS INFORMAÇÕES CONTIDAS NOS RÓTULOS DOS PRODUTOS POR PARTE DE AGRILCULTORES ASSENTADOS DE JARDIM ALEGRE, 2011

\begin{tabular}{|l|l|c|c|}
\hline \multicolumn{1}{|c|}{ Variáveis } & n & $\%$ \\
\hline $\begin{array}{l}\text { Se lê, consegue compreender as informaçōes } \\
\text { contidas nas bulas?* }\end{array}$ & $\begin{array}{l}\text { Na maioria das } \\
\text { vezes } \\
\text { Às vezes } \\
\text { Nunca }\end{array}$ & 13 & 41,9 \\
\hline & Sim & 14 & 45,2 \\
\hline $\begin{array}{l}\text { Se lê a bula, atende o que está escrito na } \\
\text { mesma?* }\end{array}$ & $\begin{array}{l}\text { Não } \\
\text { Âs vezes }\end{array}$ & 05 & 12,9 \\
\hline
\end{tabular}

"somente para quem lê, ou seja, 31 pessoas (23 sempre e 8 às vezes).

FONTE: Os autores

Divers@ Revista Eletrônica Interdisciplinar/Matinhos/Vol.6, n.1, p.1-73/jan./jun./2013 ISSN 1983-8921 


\section{DIVERS@!}

Já os produtos mais usados pelos agricultores foram: na lavoura os herbicidas e na pecuária de leite os bernicidas e carrapaticidas. Com relação ao tempo de exposição, percebe-se que $60 \%$ dos produtores gastam em média mais de 4 horas por dia na aplicação dos produtos citados, esta é uma exposição significativamente alta, já que mais de 90\% destes não utilizam os devidos equipamentos de proteção individual, como citado acima. A avaliação e análise das condições de exposição aos produtos químicos representam um grande desafio sendo que um dos principais aspectos é a avaliação dos efeitos sobre a saúde do trabalhador, mesmo porque o número de substâncias e produtos que estão agrupados sob o termo agrotóxico são muitos (BRASIL, 2006).

TABELA 5 - PERCEPÇÃO DOS RISCOS QUANTO AO USO DE AGROTÓXICOS POR PARTE DE AGRICULTORES DE JARDIM ALEGRE, 2011

\begin{tabular}{|llll|}
\hline \multicolumn{1}{|c}{ Variáveis } & & n & \% \\
\hline Considera perigoso o uso de agrotóxicos? & Sim & 38 & 95,0 \\
& Não & 02 & 5,0 \\
\hline Tem conhecimento do que é EPI & Sim & 34 & 85,0 \\
\hline Utiliza o EPI recomendado para as & Não & 06 & 15,0 \\
aplicaçốes de cada agrotóxico? & Não & 03 & 7,5 \\
\hline \multirow{3}{*}{ Se não utiliza, porquê? } & Desconforto & 37 & 92,5 \\
& Preço & 09 & 22,5 \\
& Não acha necessário & 05 & 12,5 \\
& Desconforto e Preço & 04 & 10,0 \\
& Descuido & 09 & 22,5 \\
\hline & Não conhece & 06 & 15,0 \\
\hline
\end{tabular}

FONTE: Os autores

Com relação aos sintomas de intoxicação por agrotóxicos, $75 \%$ dos entrevistados sentem algum sinal ou sintoma de intoxicação, seja durante ou após a aplicação dos produtos (tabela 6). Dos sintomas agudos citados, os mais frequentes foram: problemas estomacais $(16,7 \%)$, dor de cabeça (14,2\%) e boca seca (13,3\%). Já os sintomas crônicos mais comumente percebidos foram: insônia (23,3\%), hipertensão (20,9\%) e depressão (14\%). Dos 40 entrevistados, $35 \%$ alegaram apresentar simultaneamente sintomas agudos e crônicos, o que revela um dado ainda 


\section{DIVERS@!}

mais preocupante, pois estes sintomas somados podem demonstrar maior nível de intoxicação.

Deve-se ter cuidado com os sintomas de intoxicação aguda, pois danos causados pela intoxicação aguda podem originar efeitos tardios, nem sempre detectados em exames comuns. Mesmo os assentados tendo em sua concepção a agroecologia como o modelo de produção mais sustentável, grande parte dos agricultores produzem de maneira convencional, e fazem uso de agroquímicos de forma habitual, e em sua maioria, sem a utilização de EPIs, desde a preparação da calda (mistura da água com o produto) até a aplicação na lavoura.

TABELA 6 - SINTOMAS DE INTOXICAÇÃO EM ASSENTAMENTOS DE JARDIM ALEGRE POR UTILIZAÇÃO DE AGROTÓXICOS, 2011

\begin{tabular}{|c|c|c|c|}
\hline Variáveis & & $\mathbf{n}$ & $\%$ \\
\hline \multirow{5}{*}{$\begin{array}{l}\text { Notoul algum problema de saúde relacionado } \\
\text { à pulverização dos agrotóxicos? }\end{array}$} & Sempre & 14 & 35,0 \\
\hline & As vezes & 11 & 27.5 \\
\hline & Nunca & 10 & 25,0 \\
\hline & Quase sempre & 04 & 10,0 \\
\hline & Quase nunca & 01 & 2,5 \\
\hline \multirow{15}{*}{ Sintomas Agudos Citados } & Nenhum & 03 & 2,5 \\
\hline & Dor de cabeça & 17 & 14,2 \\
\hline & Boca seca & 16 & 13,3 \\
\hline & Tontura & 13 & 10,8 \\
\hline & Alucinações & 01 & 0,8 \\
\hline & Fraqueza & 08 & 6,7 \\
\hline & $\begin{array}{l}\text { Problemas } \\
\text { estomacais }\end{array}$ & 20 & 16,7 \\
\hline & Formigamentos & 06 & 5,0 \\
\hline & Suor frio & 07 & 5,8 \\
\hline & Coceira intensa & 08 & 6,7 \\
\hline & Lacrimejamento & 08 & 6,7 \\
\hline & Perda de apetite & 07 & 5,8 \\
\hline & Febre & 05 & 4,2 \\
\hline & $\begin{array}{l}\text { Irritação na } \\
\text { garganta }\end{array}$ & 01 & 0,8 \\
\hline & Total & 120 & \\
\hline \multirow{7}{*}{ Doenças Crônicas Citadas } & Nenhum & 15 & 34,9 \\
\hline & Depressão & 06 & 14,0 \\
\hline & Hipertensão & 09 & 20,9 \\
\hline & Insônia & 10 & 23,3 \\
\hline & Bronquite/Asma & 02 & 4,7 \\
\hline & Sinusite & 01 & 2,3 \\
\hline & Total & 43 & \\
\hline $\begin{array}{l}\text { Pessoas com sintomas Agudos e } \\
\text { Crônicos }\end{array}$ & Agudos/Crônicos & 14 & 35,0 \\
\hline
\end{tabular}

FONTE: Os autores

Divers@ Revista Eletrônica Interdisciplinar/Matinhos/Vol.6, n.1, p.1-73/jan./jun./2013 ISSN 1983-8921 


\section{DIVERS@!}

\section{CONCLUSÕES}

Os resultados da pesquisa apontam que a baixa renda e nível educacional dos agricultores deste local, com carência de informações quanto ao uso correto e seguro dos produtos químicos - o que reforça a não utilização dos EPIs - justificam as elevadas taxas de intoxicação, que afeta negativamente a saúde e qualidade de vida dos trabalhadores.

Os achados deste estudo trazem à tona a urgência e relevância - ambiental, social e sanitária - de políticas públicas para o enfrentamento dos problemas do uso de agrotóxicos no Brasil. Para tanto, é de fundamental importância as contribuições das universidades, sociedade civil e outras organizações para a implantação de modelos que superem o sistema hegemônico de produção baseado no agrotóxico e que valorizem práticas produtivas mais sustentáveis para o ambiente e a saúde pública, tal como o sistema agroecológico.

\section{REFERÊNCIAS}

ANDALÓ, Vanessa. et.al. Compatibilidade de Beauveriabassiana com Agrotóxicos Visando o Controle da Cochonilha-da-Raiz-do-Cafeeiro DysmicoccustexensisTinsley (Hemiptera: Pseudococcidae).Neotropical Entomology, Londrina, v. 33, n.4, Jul-Aug, 2004.

BRASIL. Ministério Público Federal. Decreto-lei no 7.802, de 11 de julho de 1989. Brasília. Diário Oficial [da] República Federativa do Brasil.de 12 jul. 1989.

\section{BRASIL. Ministério da Educação. Pesquisa nacional da educação na reforma agrária}

(PNERA).2005.Disponível em: <http://www.inep.gov.br/imprensa/noticias/outras/news05 12.htm >. Acesso em: 20 fev. 2011.

BRASIL. Ministério da Saúde. Sistema Nacional de Informações Toxico Farmacológicas (SINITOX).2009. Disponível em:

<http://www.fiocruz.br/sinitox_novo/cgi/cgilua.exe/sys/start.htm?sid=349 > Acesso em:13 jan. 2011.

BRASIL. Ministério do trabalho e emprego. NR 31 - Segurança e saúde no trabalho na agricultura,pecuária silvicultura, exploração florestal e aqüicultura. 2005. Disponível em: <http://portal.mte.gov.br/data/files/FF8080812BE52D26012BE52FB8382CAC/nr_31.pdf > Acesso em:06 fev. 2011.

BRASIL. Organização Pan-Americana da Saúde. Manual de vigilância da saúde de populações expostas aagrotóxicos. Brasília: M.S, 1996. 72 p.

BRASIL. Ministério da Saúde. Protocolo de Atenção à Saúde dos Trabalhadores Expostos aagrotóxicos.2006. Disponível em:

$<$ http://portal.saude.gov.br/portal/arquivos/pdf/integra_agrotoxicos.pdf

$>$ Acesso em: 23 jul. 2011.

CARRARO, Gilda. Agrotóxico e Meio Ambiente: uma proposta de ensino de ciências e de química. PortoAlegre,1997. 95 p. 